\title{
Valor Nutritivo do Feno da Rama da Mandioca (Manihot esculenta, Crantz) para Coelhos em Crescimento
}

\author{
Claudio Scapinello ${ }^{1}$, José Egmar Falco ${ }^{2}$, Antonio Claudio Furlan ${ }^{1}$, Haroldo Garcia de Faria ${ }^{3}$
}

\begin{abstract}
RESUMO - Foi conduzido um ensaio de digestibilidade para determinar o valor nutritivo do feno do terço superior da rama de mandioca, variedade "Mantiqueira" (Manihot esculenta, Crantz) em dezesseis coelhos da raça Nova Zelândia Branco, oito machos e oito fêmeas, com 50 dias de idade. Foi usado delineamento inteiramente casualizado, com dois tratamentos e oito repetições por tratamento. Na dieta teste, o feno da rama da mandioca substituiu 30\% MS da dieta referência contendo 19,30\% de proteína bruta, 12,86\% de fibra bruta e $4558 \mathrm{kcal} / \mathrm{kg}$ de energia bruta. Os coeficientes de digestibilidade aparente da matéria seca, matéria orgânica, proteína bruta, fibra bruta e energia do feno da rama da mandioca foram 41,29; 41,95; 43,72; 33,77; e 36,63\%, respectivamente. Os teores de matéria seca digestível, matéria orgânica digestível, proteína digestível, fibra bruta digestível e energia digestível para o feno da rama da mandioca foram 35,$58 ; 37,93 ; 7,69 ; 8,85 \%$; e $1639 \mathrm{kcal} / \mathrm{kg}$, respectivamente.
\end{abstract}

Palavras-chave: coelhos, digestibilidade, feno de mandioca, Manihot esculenta

\section{Nutritional Value of Cassava Foliage Hay (Manihot esculenta, Crantz) for Growing Rabbits}

ABSTRACT - A digestibility assay was carried out to evaluate the nutritional value of hay from the upper third of cassava foliage, variety "Mantiqueira" (Manihot esculenta, Crantz) in sixteen rabbits of New Zeland White breed, eight males and eight females, with 50 days of age. A completely randomized design, with two treatments and eight replicates for treatment, was used. In the test diet, cassava foliage hay replaced $30 \%$ DM of the reference diet, containing $19.30 \%$ of crude protein, $12.86 \%$ of crude fiber and $4558 \mathrm{kcal} / \mathrm{kg}$ of gross energy. The coefficients of apparent digestibility of the dry matter, organic matter, crude protein, crude fiber (\%FDN) and gross energy of hay made from the upper third of cassava foliage were: $41.29,41.95,43.72,33.77$, and 36.63\% respectively. The contents of digestible dry matter, digestible organic matter, digestible protein, digestible crude fiber FDN and digestible energy, for hay made from the upper third of cassava foliage were $35.58,37.93,7.69,8.85 \%$, and $1639 \mathrm{kcal} / \mathrm{kg}$, respectively.

Key Words: rabbits, digestibility, cassava hay, Manihot esculenta

\section{Introdução}

Entre as diversas propriedades da fibra na dieta de não-ruminantes, destacam-se o efeito diluídor da concentração energética e a interação com a utilização dos demais princípios nutritivos decorrentes do aumento da velocidade do transito digestivo.

Embora o coelho não utilize eficientemente os componentes da fibra, suas dietas apresentam teores elevados em relação à de outros animais não ruminantes (FRANK e COULMIN, 1979; LEBAS, 1983; eZINSLY et al., 1985). Isto se deve à necessidade de volume mínimo de fibra indigestível, para evitar transtornos digestivos que podem causar diarréia e, em número elevado de casos, a morte do animal, principalmente, durante a fase de crescimento (DE BLAS et al 1986).

Mais importante ainda que o volume destes componentes, é a sua qualidade, pois esta implica no funcionamento do trato digestivo e no valor nutritivo global da dieta, refletindo sobre os rendimentos produtivos (FERREIRA, 1994). Alimentos tradicionais utilizados em dietas de coelhos, como sorgo, alfafa, farelo de trigo e farelo de soja, entre outros, foram relativamente bem avaliados nas condições brasileiras por diversos pesquisadores.

Os estudos com forrageiras tropicais na formulação de dietas para coelhos são mais recentes. No Brasil, trabalhos como os de PIMENTA (1985), NASCIMENTO et al (1990), entre outros, mostram a tendência em direcionar as pesquisas em nutrição de coelhos para essa área ainda pouco estudada.

O objetivo deste trabalho foi determinar, por meio de ensaio de digestibilidade aparente, o valor nutritivo do feno do terço superior da rama de mandioca (Manihot esculenta, Crantz) cultivar "Mantiqueira".

1 Professor do Departamento de Zootecnia da Universidade Estadual de Maringá, PR.

2 Professor do Departamento de Zootecnia da Universidade Federal de Lavras, MG.

${ }^{3}$ Zootecnista do Biotério Central da Universidade Estadual de Maringá, PR. 


\section{Material e Métodos}

O experimento foi conduzido no setor de Cunicultura do Departamento de Zootecnia da Universidade Federal de Lavras.

Foram utilizados 16 coelhos da Raça Nova Zelândia Branco, oito machos e oito fêmeas, com 50 dias de idade, alojados, individualmente em gaiolas de metabolismo, providas de bebedouros automáticos e comedouros semi-automáticos e dispositivo para coleta de fezes, em delineamento experimental inteiramente casualizado, com dois tratamentos e oito animais por tratamento, sendo a unidade experimental constituída de um animal.

$\mathrm{Na}$ elaboração do feno, a rama da mandioca foi coletada aos quinze meses de idade. Esse material foi picado e espalhado em camadas de $5 \mathrm{~cm}$, em terreiro com piso de cimento, completamente exposto ao sol por um período de oito horas diárias, durante três dias consecutivos. Nesse período, o material sofreu viragens, a fim de obter secagem uniforme. A seguir, o feno foi moído para ser incorporado às rações experimentais.

Foram elaboradas uma dieta referência balanceada, para atender às exigências nutricionais de coelhos em crescimento NRC (1977), e uma dieta teste na qual o feno de rama da mandioca substituiu $30 \%$ da matéria seca da ração referência; após a mistura, as rações foram peletizadas a seco.

A composição química do feno da rama da mandioca e a composição centesimal e química da dieta referência são mostradas, respectivamente, nas Tabelas 1 e 2.

O experimento teve duração de 14 dias - sete dias para adaptação dos animais às condições experimentais e sete dias para coleta de fezes. As rações foram fornecidas no período da manhã, sendo que na fase de coleta a quantidade fornecida para cada animal foi eqüivalente ao menor consumo registrado na fase de adaptação (100g/dia).

A temperatura média registrada durante o período experimental foi de 24,9 e $11,2^{\circ} \mathrm{C}$, respectivamente, de máxima e mínima.

As fezes de cada animal foram coletadas no período da manhã, acondicionadas em sacos plásti$\cos$ e armazenados em freezer a $-10^{\circ} \mathrm{C}$. Ao final do experimento, as fezes de cada animal foram pesadas, homogeneizadas e colocadas em estufa de ventilação forçada a $55^{\circ} \mathrm{C}$ por 72 horas. Em seguida, foram moídas e acondicionadas em vidros devidamente identificados para análise laboratoriais.

Os níveis de tanino das rações experimentais e do feno da rama da mandioca, bem como os teores de
Tabela 1 -Composição química do feno de rama de mandioca (\%MS)

Table 1 - Chemical composition of cassava foliage hay (\%DM)

\begin{tabular}{lc} 
Nutriente & $(\%)$ \\
Nutrient & \\
\hline Matéria seca & 86,18 \\
Dry matter & \\
Matéria orgânica & 90,43 \\
Organic matter & \\
Proteína bruta & 17,59 \\
Crude protein & \\
Energia bruta $(\mathrm{kcal} / \mathrm{kg})$ & 4474 \\
Gross energy & \\
Fibra bruta & 26,22 \\
Crude fiber & \\
Ca & 2,06 \\
P & 0,28 \\
Tanino $(\mathrm{mg} / 100 \mathrm{~g})$ & 1014,30 \\
Tannin &
\end{tabular}

matéria seca, matéria orgânica, fibra bruta e nitrogênio dos ingredientes, das rações experimentais e das fezes foram determinados conforme métodos químicos e analíticos descritos por HORWITZ, (1975).

A energia bruta dos ingredientes, das rações experimentais e das fezes foram determinados em bomba calorimétrica (calorímetro adiabático, PARR), segundo SILVA (1981).

Os coeficientes de digestibilidade aparente (CDA) da matéria seca, matéria orgânica, fibra bruta e energia bruta do feno do terço superior da rama da mandioca foram obtidos utilizando-se as fórmulas de MATTERSON et al. (1965). Para obtenção dos valores dos nutrientes digestíveis, aplicaram-se os valores do coeficiente de digestibilidade sobre a composição química do feno da rama da mandioca.

O modelo estatístico utilizado para análise dos coeficientes de digestibilidade foi:

$$
\mathrm{Y}_{i j}=\mu+\mathrm{R}_{i}+\mathrm{E}_{i j}
$$

em que

$\mathrm{Y}_{i j}=$ coeficientes de digestibilidades dos nutrientes estudados dos animais $\mathrm{j}$, que receberam dieta $i$;

$\mu \quad=$ média geral;

$\mathrm{R}_{i}=$ efeito da dieta experimental $i$, sendo $i_{1}=$ dieta referência; $i_{2}=$ dieta teste; e

$\mathrm{e}_{i j}=$ erro aleatório associado a cada observação $\mathrm{Y}_{i j}$.

\section{Resultados e Discussão}

Os coeficientes de digestibilidade da matéria seca, proteína bruta, fibra bruta e energia bruta das rações referência e teste e do feno do terço superior da rama da mandioca encontram-se nas Tabelas $3 \mathrm{e}$ 4 , respectivamente. 
Rev. bras. zootec.

Tabela 2 - Composição centesimal e química da dieta referência

Table 2 - Chemical and percentage composition of reference diet

\begin{tabular}{|c|c|}
\hline \multicolumn{2}{|l|}{$\begin{array}{l}\text { Ingrediente } \\
\text { Ingredient }\end{array}$} \\
\hline Milho & 30,28 \\
\hline Corn & \\
\hline Farelo de soja & 18,10 \\
\hline Soybean meal & \\
\hline Farelo de trigo & 30,00 \\
\hline Wheat bran & \\
\hline Sabugo de milho & 20,00 \\
\hline Corncob & \\
\hline Sal & 0,40 \\
\hline Salt & \\
\hline $\begin{array}{l}\text { Farinha de ossos } \\
\text { Bone meal }\end{array}$ & 0,93 \\
\hline $\begin{array}{l}\text { Bacitracina de zinco } \\
\text { Zinc bacitracine }\end{array}$ & 0,05 \\
\hline Mist. Vit ${ }^{1}$ & 0,18 \\
\hline $\begin{array}{l}\text { Vitamin premix } \\
\text { Mist. } \min .^{2}\end{array}$ & 0,06 \\
\hline Mineral premix & \\
\hline $\begin{array}{l}\text { Composição analisada } \\
\text { Analyzed composition }\end{array}$ & \\
\hline Matéria seca (\%) & 83,35 \\
\hline Dry matter & \\
\hline Proteína bruta (\%) & 19,30 \\
\hline Crude protein & \\
\hline Fibra bruta $(\%)$ & 12,86 \\
\hline Crude fiber & \\
\hline $\mathrm{Ca}(\%)$ & 0,50 \\
\hline $\mathrm{P}(\%)$ & 0,44 \\
\hline Energia bruta $(\mathrm{kcal} / \mathrm{kg})$ & 4558 \\
\hline Gross energy & \\
\hline $\begin{array}{l}\text { Tanino }(\mathrm{mg} / 100 \mathrm{~g}) \\
\text { Tannin }\end{array}$ & 507,15 \\
\hline $\begin{array}{l}{ }^{1} \text { Composição por } 1,5 \mathrm{~kg} \\
1.000 .000 \mathrm{UI} ; \text { Vit E, } 5.000 \\
\mathrm{~B}_{2}, 3.300 \mathrm{mg} \text {; Vit } \mathrm{B}_{6}, 1.50 \\
\text { (Calcium panthotenate), } 16 \\
\text { Bacitracina de zinco (Zi } \\
\text { (Antioxidant), } 20.000 \mathrm{mg} ; \\
2 \text { Composição por } 0,500 \mathrm{~kg} \\
\text { Co, } 700 \text { mg; Mn, } 25.000 \mathrm{~m} \\
\text { Veiculo q.s.p (Inert filler), }\end{array}$ & $\begin{array}{l}0.000 .000 \mathrm{UI} \text {; Vit D, } \\
\text {; Vit B1,1.600mg; Vit } \\
\text { antotenato de cálcio } \\
\text { (Niacin), } 22.000 \mathrm{mg} ; \\
0 \text { mg; Antioxidante } \\
\text { Iller), } 1.500 \mathrm{~g} \\
00 \mathrm{mg} ; \mathrm{Cu}, 7.000 \mathrm{mg} ; \\
000 \mathrm{mg} ; \mathrm{Se}, 100 \mathrm{mg} ;\end{array}$ \\
\hline
\end{tabular}

Veiculo q.s.p (Inert filler), $500 \mathrm{~g}$.

Devido à escassez de pesquisas de digestibilidade desse material com coelhos, procurou-se estabelecer comparações entre valores de digestibilidade obtidos de outras forragens comuns em rações de coelhos para poder avaliar o verdadeiro valor nutritivo do feno do terço superior da rama da mandioca.

Vários fatores interferem nos coeficientes de digestibilidade dos alimentos, dificultando muitas vezes comparações e interpretações dos resultados obtidos; entre eles, o teor de fibra bruta ou alguns componentes desta fração podem interferir na utilização dos nutrientes.

ZINSLY (1972), estudando o feno de alfafa na alimentação de coelhos, obteve o valor de 57,28\% para o coeficiente de digestibilidade aparente da matéria seca, o qual foi superior ao obtido neste experimento para o feno de mandioca. MAERTENS e GROOTE (1984) também estudaram o valor nutritivo do feno de alfafa, obtendo coeficiente da digestibilidade aparente da matéria seca para coelhos de 46,40\%, também superior quando comparado ao feno da rama da mandioca. Contudo, o valor obtido neste experimento para o coeficiente de digestibilidade

Tabela 3 - Coeficiente médio de digestibilidade aparente das dietas experimentais

Table 3 - Mean coefficient of the apparent digestibility of the experimental diets

\begin{tabular}{|c|c|c|c|c|}
\hline \multirow[t]{2}{*}{$\begin{array}{l}\text { Nutriente (\%) } \\
\text { Nutrient }\end{array}$} & \multicolumn{2}{|c|}{$\begin{array}{c}\text { Ração } \\
\text { Diet }\end{array}$} & \multicolumn{2}{|c|}{$\begin{array}{l}\text { Sexo } \\
\text { Sex }\end{array}$} \\
\hline & $\begin{array}{l}\text { Referência } \\
\text { Reference }\end{array}$ & $\begin{array}{l}\text { Teste } \\
\text { Test }\end{array}$ & $\begin{array}{c}\text { Macho } \\
\text { Male }\end{array}$ & $\begin{array}{c}\text { Fêmea } \\
\text { Female }\end{array}$ \\
\hline$\overline{\mathrm{MS}}(D M)$ & $66,27^{\mathrm{a}}$ & $58,78^{b}$ & 62,60 & 62,46 \\
\hline $\mathrm{MO}(O M)$ & $66,52^{a}$ & $59,15^{b}$ & 62,92 & 62,74 \\
\hline $\mathrm{PB}(C P)$ & $80,59^{a}$ & $69,53^{\mathrm{b}}$ & 74,31 & 75,82 \\
\hline $\mathrm{FB}(C F)$ & 27,40 & 20,31 & 28,19 & 28,53 \\
\hline $\mathrm{EB}(G E)$ & $68,20^{\mathrm{a}}$ & $58,73^{b}$ & 63,57 & 63,37 \\
\hline
\end{tabular}

${ }^{1}$ Médias, na linha, seguidas de letras diferentes são diferentes $(\mathrm{P}<0,05)$ pelo teste $\mathrm{F}$.

1 Means, within a row, followed by different letters are different $(P<.05)$ by F test.

Tabela 4 - Coeficiente de digestibilidade aparente (CDA) da MS, MO, PB, FB e EB do feno da rama da mandioca

Table 4 - Coefficient of apparente digestibility (CAD) of dry matter, organic matter, crude protein, crude fiber and gross energy of cassava foliage hay

\begin{tabular}{lc}
\hline $\begin{array}{l}\text { Nutriente } \\
\text { Nutrient }\end{array}$ & CDA $(\%)$ \\
\hline Matéria seca & 41,29 \\
$\begin{array}{l}\text { Dry matter } \\
\text { Matéria orgânica } \\
\text { Organic matter }\end{array}$ & \\
Proteína bruta & 41,95 \\
$\begin{array}{l}\text { Crude protein } \\
\text { Fibra bruta }\end{array}$ & 43,72 \\
$\begin{array}{l}\text { Crude fiber } \\
\text { Energia bruta } \\
\text { Gross energy }\end{array}$ & 33,77 \\
\hline
\end{tabular}


aparente da matéria seca, de 41,29\%, foi superior aos encontrados por FERREIRA et al. (1997), que, estudando o feno de guandu, feno de soja perene e palha de feijão, encontraram valores de 24,0; 34,22; e $30,24 \%$ respectivamente.

O coeficiente de digestibilidade da proteína bruta determinado para o feno da rama da mandioca, de $43,72 \%$, foi inferior ao obtido por RAHARJO et al. (1986), em experimento desenvolvido com capimelefante para coelhos, que foi de $64,65 \%$. Trabalhando com feno de feijão guandu para coelhos em crescimento, FERREIRA et al. (1997) encontraram valor para o coeficiente de digestibilidade aparente da proteína de $25,64 \%$, que é inferior quando comparado ao feno de mandioca.

O coeficiente de digestibilidade aparente da fibra bruta do feno da rama de mandioca apresentou valor de $33,77 \%$, o qual é semelhante aos encontrado por ZINSLY (1972) e CARREGAL e TAKAHASHI (1983) de 32,17 e 31,50\%, estudando o feno de soja perene para coelhos da raça Chinchila e Califórnia, respectivamente. Porém, o resultado obtido no presente trabalho é superior ao encontrado por FERREIRA et al. (1997), que, trabalhando com feno de rami, feno de guandu, feno de soja perene e palha de feijão para coelhos da raça Nova Zelândia Branco, encontraram os valores para o coeficiente de digestibilidade da fibra bruta de 22,78; 27,41; 8,34; e $28,00 \%$, respectivamente.

$\mathrm{O}$ valor de coeficiente de digestibilidade aparente da energia bruta obtido neste trabalho foi de $36,63 \%$, sendo superior ao obtido por FERREIRA et al. (1997), que encontraram valores de 24,62; 33,68; e $27,58 \%$, trabalhando com com feno de guandu, feno de soja perene e palha de feijão, respectivamente.

Constatou-se que o feno da mandioca possui baixos coeficientes de digestibilidade, quando comparado ao feno de alfafa, que é mais utilizado em rações para coelhos, em virtude da presença de taninos livres e taninos condensados que prejudicam a digestibilidade dos nutrientes deste material. Essa afirmação tem respaldo no trabalho de REED et al. (1982), que, buscando explicações para o baixo valor nutritivo da rama da mandioca, citam a presença de taninos livres e condensados. Esses autores salientam ainda que este efeito depressivoé ainda maior em monogástricos.

Os teores de nutrientes digestíveis obtidos para o feno do terço superior da rama da mandioca, considerando os resultados da composição química do feno da rama da mandioca e os coeficientes de digestibilidade aparente, são apresentados na Tabela 5.
Tabela 5 - Matéria seca digestível, matéria orgânica digestível, proteína digestível, fibra digestível e energia digestível do feno da rama da mandioca

Table 5 - Digestible dry matter, digestible organic matter, digestible protein, digestible fibre and digestible energy of cassava foliage hay

\begin{tabular}{|c|c|}
\hline $\begin{array}{l}\text { Nutriente digestível } \\
\text { Digestible nutrient }\end{array}$ & $(\%)$ \\
\hline Matéria seca digestível & 35,58 \\
\hline Digestible dry matter & \\
\hline $\begin{array}{l}\text { Matéria orgânica digestível } \\
\text { Digestible organic matter }\end{array}$ & 37,93 \\
\hline Proteína digestível & 7,69 \\
\hline Digestible protein & \\
\hline $\begin{array}{l}\text { Fibra bruta digestível } \\
\text { Digestiblefiber }\end{array}$ & 8,85 \\
\hline $\begin{array}{l}\text { Energia digestível }(\mathrm{kcal} / \mathrm{kg}) \\
\text { Digestible energy }\end{array}$ & 1639 \\
\hline
\end{tabular}

\section{Conclusões}

Os coeficientes de digestibilidade aparente da matéria seca, matéria orgânica, proteína bruta, fibra bruta e energia bruta do feno do terço superior da rama de mandioca foram, respectivamente, 41,29; 41,$95 ; 43,72 ; 33,77$; e $36,63 \%$.

Os teores de matéria seca digestível, matéria orgânica digestível, proteína digestível, fibra digestível e energia digestível foram, respectivamente, $35,58 \%$; $37,93 \% ; 7,69 \% ; 8,85 \%$; e $1639 \mathrm{kcal} / \mathrm{kg}$.

\section{Referências Bibliográficas}

CARREGAL, R.D., TAKAHASHI, R. Comparação entre o valor nutritivo dos fenos de soja perene (Glycine wigtii) e amoreira (Morus alba) através da digestibilidade aparente. In: SOCIEDADE BRASILEIRA DE ZOOTECNIA 20, 1983, Pelotas. Anais... Pelotas: SBZ, p.66, 1983.

DE BLAS, J.C., SANTOMÁ, G., CARABAÑO, R.et al. 1986. Fiber and starch levels in fattening rabbit diets. J. Anim. Sci., 63(6):1897-1904.

FERREIRA, W. M. Os componentes da parede celular vegetal na nutrição de não ruminantes. In: SIMPÓSIO INTERNACIONAL DE PRODUÇÃO DE NÃO RUMINANTES, Maringá, PR, 1994. Anais...Maringá, p.85-113, 1994.

FERREIRA, W.M., SARTORI, A.L., SANTIAGO, G. S. et al. 1997. Digestibilidade aparente dos fenos de rami (Boehmeria nivea, G.), guandu (Cajanus cajan, L.), soja perene (Glycine wightii, V.) e da palha de feijão (Phaseolus vulgaris, L) em coelhos na fase de crescimento. Arq. Bras. Med. Vet. Zootec., 49(4):465-472.

FRANCK, Y., COULMIN, J.P. 1979. Utilisation de la paille de blé broyée comme source de cellulose dans les aliments lapins à l'engrassement; comparaison de deux taux de cellulose. Ann. Zootech., 28:131.

HORWITZ, W. 1975. Official methods of analysis of association of official analysis chemists. $12 \mathrm{ed}$. Washington, Association 
Rev. bras. zootec.

of Official Analysis Chemists. 957p.

LEBAS, F. 1983. Small-ecale rabbit prodution, Feeding and management systems. Word Anim. Rev., 46:11-17.

MAERTENS, L., GROOTE, G. Digestibility and digestible energy content of a number of feedstuffs for rabbits. In: WORD RABBIT CONGRESS, 3, 1984, Roma. Proceedings... Roma: 1984. p.244-251.

MATTERSON, L.D. POTTER, L.M., SINGSEN, E.P. 1965. The metabolizable energy of feed ingredients for chickens. Research Report, 7:3-11.

NASCIMENTO, M. C. L., TAFURY, M.L., MELLO, H.V. et al. Fenos de aveia (Avena strigora, S.) e de rami (Bohemeria nivea, G.) para coelhos em crescimento. In: REUNIÃO ANUAL DA SOCIEDADE BRASILEIRA DE ZOOTECNIA, 27, 1990, Campinas. Anais... Campinas: 1990. p.208.

NATIONAL RESEARCH COUNCIL - NRC. 1977. Nutrients requeriment of rabbits. Washington, National Academy of Science. 30p.

PIMENTA. W.N.A. Desempenho de coelhos em crescimento submetidos à ração balanceada e feno de cunhã (Clitoria ternatea, L.) e de rami (Boehmeria nivea, G.) e de mandioca (Manihot esculenta. C.). Fortaleza: UFC, 1985. 51p. Dissertação (Mestrado em Zootecnia) - Universidade Federal do Ceará, 1985

RAHARJO, Y.C., CHEEKE, P.R., PATTON, N.M. et al. 1986. Evaluation of tropical forages and by products feeds for rabbit production. Nutrient digestibility and effect of heat treatment. J. Appl. Rabbit Res., 9:56-66.

REED, J.D., MCDOWELL, R.E., VAN SOEST, P.J. et al. 1982.
Condensed tannins: A factor limiting the use of cassava forage. J. Sci. Food Agric., 33(3):213-220.

SILVA, D.J. 1981. Análise de alimentos: métodos químicos e biológicos. Viçosa: UFV. 166p.

ZINSLY, C.F. Eficiência do coelho comparada à do carneiro na determinação da digestibilidade de nutrientes de algumas leguminosas forrageiras. Piracicaba, ESALQ/USP, 1972, 84p. Tese (Doutorado em Zootecnia) - Escola Superior de Agricultura “Luiz de Queiroz”/Universidade de São Paulo, 1972.

ZINSLY, C.F., FERREIRA, W.M. CARREGAL, R.D. Nutrição e alimentação In: ENCONTRO NACIONAL DE CUNICULTURA, I, 1985, Belo Horizonte. Anais... Belo Horizonte: 1985, 9p.

Recebido em: 28/05/98

Aceito em: 11/02/99 